\title{
Moving toward a smarter power grid: A proposed strategy for strengthen smart grid roadmaps through a case study
}

\author{
Moaad Aboumalik ${ }^{\mathrm{a} *}$, Mohamed EL Brak ${ }^{\mathrm{b}}$, Mohamed Essaaidi ${ }^{\mathrm{a}, \mathrm{c}}$ \\ ${ }^{a}$ Physic Dept. - Faculty of Science, Abdelmalek Essaadi University, Tetuan, Morocco \\ ${ }^{b}$ Faculty of Sciences and Techniques, Abdelmalek Essaadi University, Tangier, Morocco \\ ${ }^{c}$ ENSIAS College of Engineering, University of Mohamed $5^{\text {th }}$, Rabat, Morocco
}

\begin{abstract}
Connecting Renewable Energy Sources and Systems (RESSs) to utility power grids is one of the most ambitious endeavors of Smart Grid (SG) development in many countries. The challenge of integrating RESSs is that it is highly variable, intermittent and unreliable. Electric power grids must therefore absorb this variability with a portfolio of solutions. Today, we are already seeing strong signs of convergence in the development of the power grid in many developing and emerging countries, and the transformation of the energy system through the efforts of different stakeholders in this field: academia as well as large and small businesses, who continue to push the boundaries of knowledge in the energy sector. On the other hand, governments need to come up with policies that promote innovation while not jeopardizing the SG infrastructure. This article has been arranged to introduce the subject in the first section, the second section presents the concept of a SG, then we involve in the third section a case study for Moroccan SG roadmap and the problem statement related to legislative context, which considered as a major obstacle for SG transitions not only in Morocco, but in some other developing countries. Hence, the last sub-section proposes an efficient strategy as a solution to overcome some specific issues even in technology or in regulatory, while the forth section was devoted to the conclusion.
\end{abstract}

Keywords: Smart grid, renewable energy sources and systems, concept, strategy.

\section{Introduction}

The use of RESSs increased considerably due to the necessity to reduce greenhouse gas emissions and developing alternative energy sources beside oil and gas $[1,2]$. However, integrating RESSs on a large scale is one of the main challenges in developing SG. Many authors were affirmed in their papers [3, 7] it is perceived that the SG infrastructure will be highly based on RESSs, microgrids (MGs) in community, Advanced Metering Infrastructures (AMIs), intelligent substations, and self-healing power networks. In fact, these concepts and technologies are able to maintain major services to customers and power utilities either in normal situations or in blackouts scenarios and whereupon enhance the power quality, and improve the reliability of the distribution networks. Leading countries in SG investment and development (see the top ten countries for SGs investments in 2010 in the Table 1), has developed efficient action plans and strategic energy policies [8,9] to ensure the integration of an energy portfolio, that supports a smarter ecosystem which provides free and deregulated electricity markets [10], and a stronger economy, while other developing and emerging countries try to achieve SG planning within its economic and energy potentials [11].

Appendix A shows the updated SG Top markets report for US exporters in January 2017 and the financial report about global new investment in RESSs by technology in both: developed and developing countries.

\footnotetext{
* Manuscript received April 23, 2018; revised January 8, 2019.

Corresponding author. Tel.: +212-628-039-147 ; E-mail address: moaad.aboumalik@gmail.com

doi: $10.12720 /$ sgce.8.2.131-139
} 
Table 1. Top ten countries for federal SG investment in 2010 (Adapted from [9]).

\begin{tabular}{ll}
\hline CHINA & 7.32 billion US Dollars \\
USA & 7.09 billion US Dollars \\
JAPAN & 849 million US Dollars \\
S. KOREA & 824 million US Dollars \\
SPAIN & 807 million US Dollars \\
GERMANY & 397 million US Dollars \\
AUSTRALIA & 360 million US Dollars \\
UK & 290 million US Dollars \\
FRANCE & 265 million US Dollars \\
BRAZIL & 204 million US Dollars \\
\hline
\end{tabular}

\section{SG Concept}

\subsection{Defining the $S G$}

According to the European Technology Platform, "A Smart Grid is an electricity network that can intelligently integrate the actions of all users connected to it-generators, consumers and those that do both -in order to efficiently deliver sustainable, economic and secure electricity supplies. " [12].

The US Federal Energy Regulatory Commission defined it as " An electrical grid which includes a variety of operational and energy measures including Smart Meters, Smart Appliances, Renewable Energy Resources, and Energy Efficiency Resources" [13]. Appendix B shows the IEEE version to move from today's electricity supply chain toward a SG, which involves DGs, information networks, and system coordination [14].

Another definition for grid modernization by the US Department of Energy stating that: "An automated, widely distributed energy delivery network, Smart Grid will be characterized by a two-way flow of electricity and information and will be capable of monitoring everything from power plants to customer preferences to individual appliances. It incorporates into the grid the benefits of distributed computing and communications to deliver real-time information and enable the near-instantaneous balance of supply and demand at the device level" [15].

\subsection{Conceptual model}

SG can be conceptualized as an extensive cyber - physical system, this conceptual model intends to foster understanding of SG operational intricacies but not to prescribe how it will be implemented (it is not a design diagram that defines a solution and its implementation) $[15,16]$. Appendix $C$ shows the interaction of different actors in different smart grid domains through secure communication and electrical layers, it is the conceptual diagram of SG as defined by the US National Institute of Standards and Technology, while Table 2 describes the seven domains in the SG conceptual model including: Customers, Markets, Service Providers, Operations, Bulk Generation, Transmission and Distribution.

Table 2. The seven domains and action plans in the NIST SG conceptual model framework [16].

\begin{tabular}{ll}
\hline Domain & Responsibility and Action plan in the Domain \\
\hline Bulk & The generators of electricity in bulk quantities. \\
Generation: & May also store energy for later distribution. \\
\hline Transmission & $\begin{array}{l}\text { The carriers of bulk electricity over long distances. } \\
\text { May also store and generate electricity. }\end{array}$ \\
\hline Distribution & The distributors of electricity to and from customers. \\
& May also store and generate electricity. \\
\hline Customers & $\begin{array}{l}\text { Traditionally, three types are discussed, each with its own domain: residential, } \\
\text { commercial, and industrial. In SG, customers can buy and resell electricity in real }\end{array}$ \\
& time and anywhere because of deregulated electricity market operation. \\
\hline Service Providers & The organizations providing technology solutions and services to electrical \\
\hline
\end{tabular}


customers and utilities. Also, develop standards with government stakeholders and industrials.

\begin{tabular}{ll}
\hline Operations & $\begin{array}{l}\text { The managers of the movement of electricity. Provide optimum planning and } \\
\text { develop business models. }\end{array}$ \\
\hline Markets & $\begin{array}{l}\text { Collaboration between sector stakeholders, operators and participants in deregulated } \\
\text { and free electricity markets. }\end{array}$ \\
\hline
\end{tabular}

\subsection{SG technologies and features}

Utility power networks are losing hundred dollars per year in grid outages and blackout situations, especially in the transport and distribution levels, indeed, SG technologies and features will play a major role to enhance reliability and improve stability of the medium and low voltage of electric devices and systems. Many standards are now moving to SG specifications such as wired communication protocols that are migrating from conventional serial interfaces towards high speed Ethernet [17].

Moreover, to liberalize the electricity market and to have a good local communication capabilities, SGs in their local and substation levels (Neighborhood Area Networks NANs) contains Wireless Mesh Networks based intelligent metering infrastructures (AMI networks) which allow to operators as well as customers real time measurements and permit flexible resizing operation of the energy needs depending on normal, or blackouts scenarios. Appendix D summarizes some required communication technologies for Smart Metering, which can be implemented to move towards a SG infrastructure [18].

\section{Strategy to Strengthen the SG Roadmap: Case Study for Morocco}

\subsection{RESS potentials and targets}

Having benefited from a large solar field and a very high wind velocity, Morocco has placed renewable energy potentials in its national strategy for sustainable development [19, 20]. Indeed, government guidelines have been established with the objective of reducing $\mathrm{CO} 2$ emissions and global warming as well as the efficient exploitation of RESSs. In this regard, as an example, the project NOOR that aims to develop a minimum capacity of $2000 \mathrm{MW}$ by 2020, through solar PV and CSP projects that are installed in: Ouarzazate, Laayoune, Boujdour, Midelt and Tata, and are expected to generate investments of more than 9 billion dollars by 2020 (Elimination of 3.7 million tones of CO2) [21].

Moreover, Morocco is strategically planning to increase the total renewable energy integration to $42 \%$ by the year 2020 and $50 \%$ in 2050 [22]. In 2013, the total installed power generation capacity was 7,342 MW [21]. This consists of 5,077 MW of thermo - solar power stations, 1,770 MW of hydroelectric power including $464 \mathrm{MW}$ of hydro pumped storage, while the wind generation plants provide the remaining 495 MW.
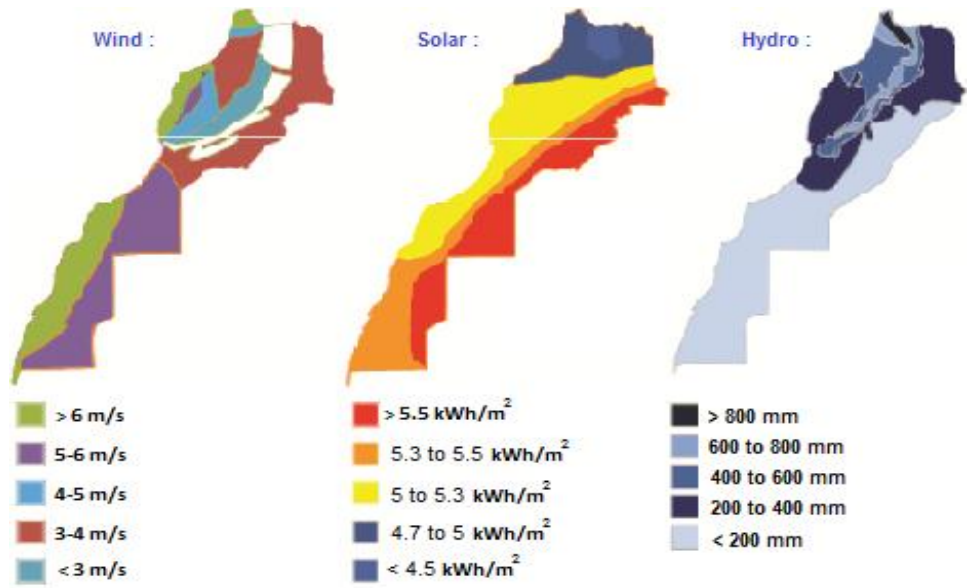

Fig. 1. The energy-mix map in Morocco updated in 2016 (adapted from [23]). 
The year of 2014 was marked by a growing contribution of distributed renewables to satisfying domestic demand with: $5.7 \%$ besides $4.2 \%$ in 2013 as shown in table 2 . By the year 2020, the total renewable energy integration will increase to $42 \%$ with solar, wind and hydroelectric power which contributing by $14 \%[22]$.

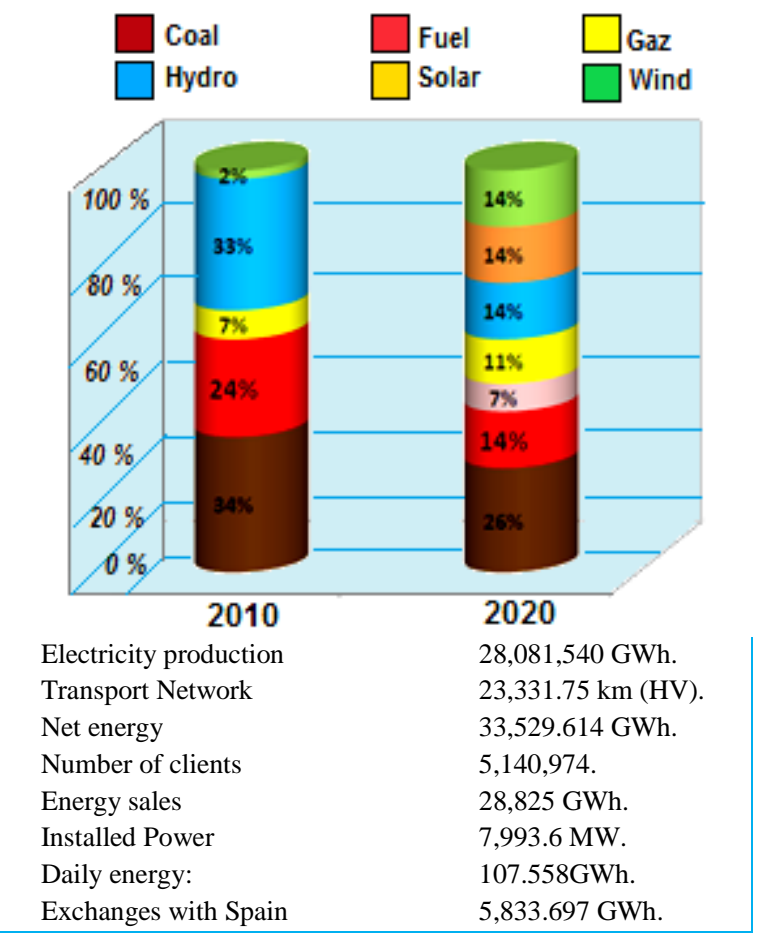

Fig. 2. Evolution of installed capacity of energy-mix between 2010-2020 (adapted from [23]).

\subsection{SG transformation challenges and issues}

The electricity supply chain is managed by ONEE power utility grid in Morocco, which carries out purchasing and sales mechanisms, notably via interconnection with neighbor countries as Algeria, and Spain, and sells a major part of electricity to the low voltage distribution operators such as LYDEC in Casablanca and RADEMA in Marrakech [24]. Whereas ONEE grid is characterized by a unidirectional flow of electricity: from production to consumers. However, the SG add information and communication technologies, enabling a Multi - directional flow of electricity and information as well as a real-time monitoring and management capability and a good mastery of supply and request. On the other hand, the ability of customers to install renewable energy that feeds into the grid is governed by laws. RESSs related law already covers several legal aspects and issues concerning the integration of renewable energy according to the act "58-15" amending and supplementing that of "13-09" [25, 27].

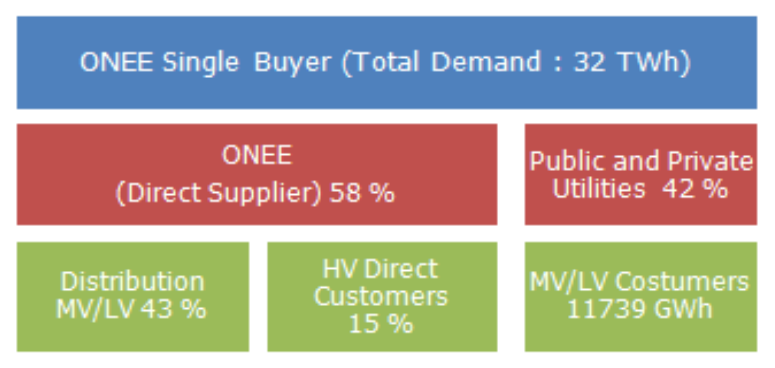

Fig. 3. The balance of supply-demand and power flow in Moroccan electricity grid Adapted from [24] 
Fig. 3 shows the balance of supply-demand and power flow in Moroccan electricity grid, while Table 3 summarizes the legal framework, which indicates that the Moroccan regulation allows renewable energy producers to feed surplus electricity to medium and low voltage as well as the high voltage grid of ONEE. Nevertheless, the operator should not sell more than $20 \%$ as a surplus of the annual production (see Table 3). Thus, the challenge to purchase and resell electric energy, as is required for SG, which will be possible if an AMI infrastructure is deployed to allow a good grid management.

Table 3. Legal framework for RESSs in Morocco [27].

\begin{tabular}{|c|c|}
\hline $\begin{array}{l}\text { Sale of the } \\
\text { excess } \\
\text { production }\end{array}$ & $\begin{array}{l}\text { Possibility of selling the excess electricity production from } \\
\text { renewable sources as part of the facilities connected to the national } \\
\text { network of High Voltage (HV) and Very High Voltage (VHV) and } \\
\text { of medium voltage and low voltage network to ONEE or to } \\
\text { distribution system operators. The operator shall not sell more than } \\
20 \% \text { as a surplus of the annual production. The commercial terms } \\
\text { and conditions of the surplus's redemption are set by regulation }\end{array}$ \\
\hline $\begin{array}{l}\text { Opening of the } \\
\text { Low Voltage } \\
\text { renewable } \\
\text { energy market }\end{array}$ & $\begin{array}{l}\text { The opening of access to law voltage distribution network will } \\
\text { take part in law 13-09 ( } 5^{\text {th }} \text { Article), previously confined to the HT, } \\
\text { THT and MT. This would allow the development of industrial sector } \\
\text { of small and medium facilities, including photovoltaics and creating } \\
\text { jobs in the renewable energy sector. The access to the law voltage } \\
\text { electric network will be subordinated to "the terms and conditions set } \\
\text { by regulation". }\end{array}$ \\
\hline
\end{tabular}

However, SG technology is made up of Multi-microgrid systems while the availability of electric power in Morocco depends in part on the availability of the ONEE Grid Control System. Therefore, we must develop a strategy that meets the regulations of the government and facilitates the way to go toward a SG network.

Another challenge that should taking into account by government is about the electricity price of RESSs, especially in the low voltage, which is relatively high if we compared it to the international average prices [28], thus, "Morocco has no choice but to strengthen its local capacity for energy production and to open the way to promising energy supply investments. It must continue its efforts to make alternative and renewable energy a cornerstone of the national energy policy" stating by King Mohammed $6^{\text {th }}[29]$.

\subsection{Proposed solutions}

We proposed an efficient management strategy to migrate current power grid to future smart grid in Morocco. The evolution of this strategy, which summarized in Figure 4, can be described as explained in the following:

- First stage :

The Implementation of RESSs in houses and commercial buildings and the use of NAN networks in order to facilitate management and control, commercial connections will need special contracts and integrations strategies, as they will produce higher amount of energy. However, rules need to be developed to outline the physical and geographical boundaries of contracts. These rules need to be based on scientific data proven by using modeling and conducting experiments.

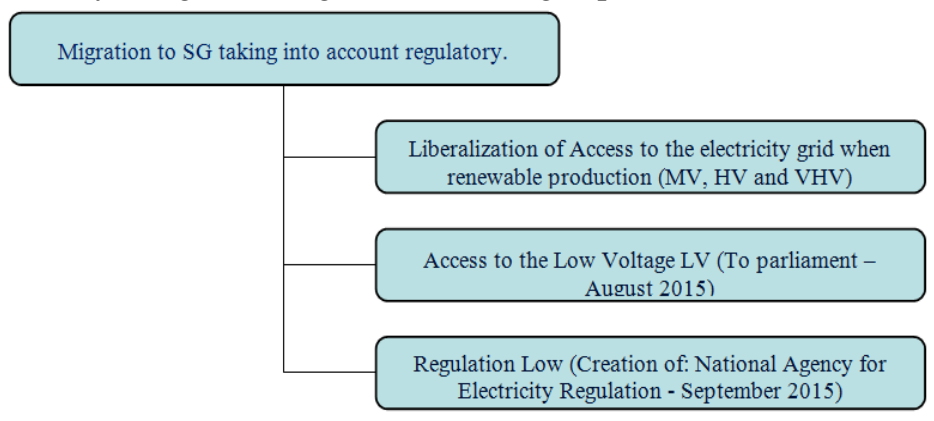

Fig. 4. SG acts framework taking into account regulatory. 
- Second stage:

A management strategy for special cases where the amount of aggregated RESSs has big impact in local and global services. In particular, neighborhood collaborating to groom the power generated in a big area may have significant impact on the grid from control and information overload point of views. We can summarize in the Table 4 as well as Figure 4, the major characteristics to go toward a SG in Morocco, even in regulatory or in technological plans:

Table. 4 Major Smart Grid features in terms of technologies.

\begin{tabular}{ll}
\hline Electrical power network & Smart Grid features \\
\hline Few integrated RESSs & Distributed RESSs \\
Unidirectional electricity flow & Bidirectional electricity flow \\
One way communications & Multi-way communications \\
Few sensors and actuators & Intelligent Electronic Devices and WSNs \\
Manual monitoring and restoration & Self-Healing and HAN / NAN \\
Conventional Substations & Multi-MG (in Islanded and Connected modes) \\
\hline
\end{tabular}

- Third Stage:

This is based on a comprehensive active power management system that implement controls at the primary, secondary and tertiary controls. Different control levels have different timing requirements that include real time communication and an efficient power flow control. These managements are implemented at the transmission and distribution networks levels.

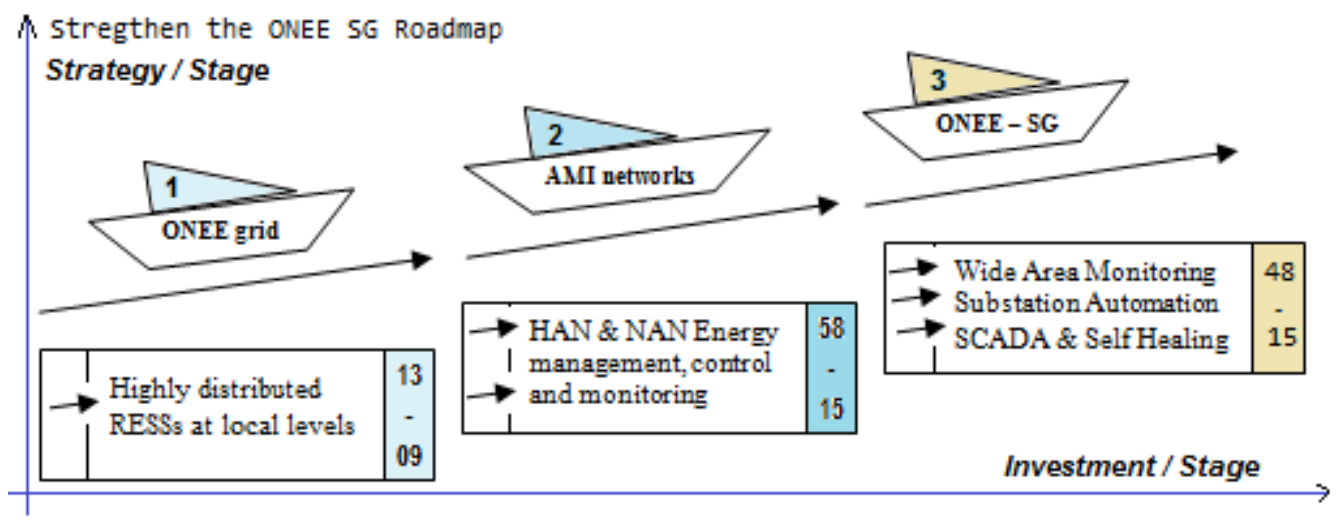

Fig. 5. Migration to the SG using the proposed strategy and the legal frameworks.

Figure 5 shows the three stages that ensure the ONEE grid modernization in terms of architectures and SG levels taking into account the acts: 13-09, 58-15 and 48-15, while Figure 6 presents the transition of the electricity market from the Power Purchase Agreement (PPA) model [30] to a De-regulated system. Few modifications in the act 58-15 will enable the proper functioning of the free RESSs market and then can regulate the access of auto-producers to the ONEE utility grid thought Net-metering approach [31]. Finally, IPP market operations [30], with free RESSs markets will liberalize the entire ecosystem, providing that the National Regulatory Authority of Electricity (Act: 48-15) enables a clear laws in this regard.

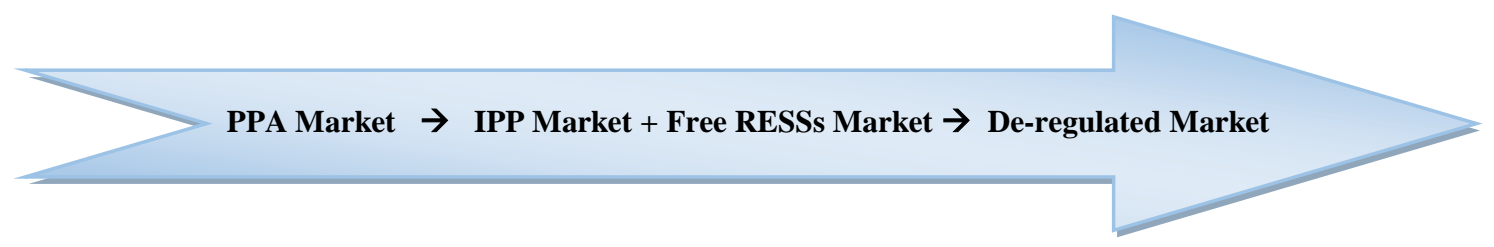

Fig. 6. The transition of the electricity market for developing and emergent countries (Adapted from [30]). 


\section{Conclusion}

As costs of SG technologies decline, integration capacity of RESSs will grow in low and medium voltage levels. This will bring challenges at deploying microgrids in power network for developing and emerging countries including Morocco as we have pointed out here. This paper presents an innovative strategy for strengthen the SG roadmap taking into consideration regulatory issues, free market needs and SG standards and technologies. We illustrated the SG implication in developing countries by a case study of distributed RESSs in the ONEE Moroccan electric grid, based on national regulations in this field. Moreover, there are many other techniques and financial challenges that will be exist, especially those related to the stability and congestion which shall taken into account if not deployed with the appropriate energy balance and secure access and controls. Therefore, it is concluded that a good action plans in terms of RESSs regulatory and standard frameworks in conjunction with SG technologies will be the key solutions to solve a lot of problems in the electric power networks, but they also may create many new challenges related to market adoptions and old legal frameworks that were already followed by governments and utilities.

\section{References}

[1] Eduardo FC, et al.,. Control for Renewable Energy and Smart Grids. (Research report 2012). [Online]. Available : http://ieeecss.org/sites/ieeecss.org/files/documents/IoCT-Part1-06RESG.pdf

[2] Baul TK et al,. A comparative study on household level energy consumption and related emissions from renewable (biomass) and non-renewable energy sources in Bangladesh , (Energy Policy 2018)

[3] Joe M, Modern Grid Strategy Team. Understanding the smart grid: Features, Benefits and Costs. (July 8, 2008) [Online]. Available : https://www.smartgrid.gov/files/understanding_the_smart_grid_07-2008.pdf

[4] Desai JV et al,. Investigations on harmonics in smart distribution grid with solar PV integration. Technol Econ Smart Grids Sustain (Energy 2016) 1.

[5] Tawfiq M. Aljohani et al. Comparison comparison of the effect of the distributed generators vs new distribution substation on the reliability of the power distribution grid. International Journal of Smart Grid and Clean Enegy, October 2016; 5(4): 252258.

[6] Mohamed RA et al,. A wireless mesh architecture for the advanced metering infrastructure in residential smart grids, In: IEEE Green Technologies Conference, Denver, CO, USA 2013.

[7] Benjamin S. et al 2015 New J. Phys. 17015002 "Decentral Smart Grid Control” (New J. Phys 2015)

[8] Renewable Energy Policy Network for the $21^{\text {st }}$ Century. Research report (Renewables 2014 Global Status Report). [Online]. Available:http://www.ren21.net/Portals/0/documents/Resources/GSR/2014/GSR2014_full\%20report_low\%20res.pdf

[9] General Electric. Top 10 nations for smart grid investment. Research report. (Zpryme Research \& Consulting2010) [Online]. Available: http://www.reliableplant.com/Read/27393/Nations-smart-grid-investment

[10] Packiasudha M, Suja S. FACT device for reactive power compensation in the deregulated electrical power environment. International Journal of Power Electronics and Drive System, December 2015; 6(4): 730-735.

[11] The US Department of Commerce, (International Trade Administration), The updat Smart Grid Top Markets Report for US Exporters - version, January 2017. (Research report 2017). [Online] Availibale: https://www.trade.gov/topmarkets/pdf/Smart_Grid_Top_Markets_Report.pdf

[12] Jenkins et al.,. An Overview of the Smart Grid in Great Britain. Engineering, Volume 1, Issue 4, December 2015, Pages 413421 Available at: https://www.sciencedirect.com/science/article/pii/S2095809916300224

[13] United States Federal Energy Regulatory Commission. Federal Energy Regulatory Commission Assessment of Demand Response \& Advanced Metering. (Research report 2017).

[14] Frank K et al. 100\% Green Computing At The Wrong Location (researchgate 2012) [Online] Available: https://www.researchgate.net/publication/258858691_100_Green_Computing_At_The_Wrong_Location

[15] Cen-Cenelec-Etsi-Smart Grid coordination Group. Research report. Smart Grid Reference Architecture, November 2012

[16] Architecture Team assembled by EPRI. Smart Grid Conceptaul Model. Research report. Smart Grid Interoperability Panel, Version 1 March 15, 2010

[17] Geoff Zeiss, web of geospatial.blogs. NIST Releases Framework and Roadmap for Smart Grid Interoperability Standards 1.0 (2010) [Online]. available: http://geospatial.blogs.com/geospatial/2010/02/nist-releases-framework-and-roadmap-for-smartgrid-interoperability-standards-10.html

[18] Nikoleta A. et al., Review-Telecommunication Technologies for Smart Grid Projects with Focus on Smart Metering Applications (Energies 2016, 9(5), 375)

[19] Kousksou T. et al. Renewable energy potential and national policy directions for sustainable development in Morocco. Renewable and Sustainable Energy Reviews, July 2015; 47: 46-57. 
[20] Kousksou T, Allouhi A, Belattar M, Jamil A, El Rhafiki T, Zeraouli Y. Morocco's strategy for energy security and low-carbon growth. Energy, May 2015; 84(1): 98-105.

[21] Mustapha A. Renewable Energy University Network in collaboration with GIZ "Gesellschaft für Internationale Zusammenarbeit (GIZ)". Training-Programme of: “Journée scientifique sur l'énergie éolienne, Jeudi 25 mai 2017 Ecole Hassania des Travaux Publics, Casablanca . [Online] Availibale: http://www.reunet.ma/Eol/Depliant-programme.pdf

[22] Moroccan Government, Ministry of Energy, Mines, Water and the Environment (Ministere de l'Energie, des Mines, de l'Eau et de l'Environnement), 2013. [Online]. Available: http://www.mem.gov.ma/SitePages/GrandChantiersEn/DERegulationOfSector.aspx

[23] Hassane D, ONEE-Renewable Energy in Morocco -Jan2012-RETEM.ppt from the Proceedings of Renewable Energy: Technology and Efficient Management 2012 Available at: https://sites.google.com/site/retm2012ma/proceedings

[24] Tayeb Amegroud, Morocco's Power Sector Transition: Achievements and Potential, IAI and OCP Policy Center partnership February 2015, PP-15/09. Research report. http://www.ocppc.ma/sites/default/files/OCPPC-PP1509.pdf

[25] Federal Ministry For Economic cooperation and Development (Germany). Legal Frameworks for Renewable Energy. (Research report 2013). [Online]. Available: https://www.icafrica.org/fileadmin/documents/Knowledge/GIZ/Legal\%20Frameworks\%20for\%20Renewable\%20Energy.pdf

[26] Michal N. et al., Climate change legislation in Morocco, an exception from the 2015 Global Climate Legislation Study (Research report 2015). [Online] Available: http://www.lse.ac.uk/GranthamInstitute/wp-content/uploads/2015/05/MOROCCO.pdf

[27] Ministry of Energy, Mines, Water and the Environment (Ministere de l'Energie, des Mines, de l'Eau et de l'Environnement), 2013. [Online]. Available: http://www.mem.gov.ma/SitePages/GrandChantiersEn/DERegulationOfSector.aspx

[28] IRENA (2018), International Renewable Energy Agency, Abu Dhabi: Renewable Power Generation Costs in 2017. [Online] Available: https://www.irena.org/-/media/Files/IRENA/Agency/Publication/2018/Jan/IRENA_2017_Power_Costs_2018.pdf

[29] Adriani, B., et al., Lighting up the Kingdom of Morocco. Research report. Energy strategy and recent developments in power projects. Linklaters. 2013.

[30] Choukri, K., Naddami, A. \& Hayani, S. Renewable energy in emergent countries: lessons from energy transition in Morocco. Energ Sustain Soc (2017) 7: 25. [Online]. Available: https://doi.org/10.1186/s13705-017-0131-2

[31] Mohammed H. Ministry of Energy, Mines, Water and Environment., Moroccan electricity sector regulation, COP22 Marrakech, November 16th, 2016 [Online]. Available: http://dkti-maroc.org/wp-content/uploads/sites/61/2016/12/1.Moroccan-electricity-sector-regulation.pdf

\section{Appendix A:}

A-1. The updated Smart Grid Top Markets Report for US Exporters - Version of January 2017 (Adapted from [11]):

\begin{tabular}{|c|c|c|c|c|c|c|c|c|c|}
\hline & Mexico & 11 & China & 21 & Denmark & & Nigeria & & Costa Rica \\
\hline 2 & Canada & 12 & Germany & 22 & Singapore & 32 & Italy & 4 & Morocco $>$ \\
\hline 3 & UK & 13 & Ireland & 23 & Turkey & 33 & Israel & 43 & Ghana \\
\hline 4 & India & 14 & Vietnam & 24 & Sweden & 34 & Thailand & 44 & Romania \\
\hline 5 & Australia & 15 & Malaysia & 25 & Kenya & 35 & Brazil & 45 & Peru \\
\hline 6 & Korea & 16 & Philippines & 26 & Spain & 36 & Argentina & 46 & Bulgaria \\
\hline 7 & Japan & 17 & Indonesia & 27 & Ethiopia & 37 & Colombia & 47 & Nicaragua \\
\hline 8 & Egypt & 18 & France & 28 & \begin{tabular}{|l} 
Poland \\
\end{tabular} & 38 & South Africa & 48 & New Zealand \\
\hline 9 & Saudi Arabia & & Finland & 29 & Austria & 39 & Portugal & & Russia \\
\hline & Chile & 20 & Netherlanc & 30 & Belgium & & Crech Re & & \\
\hline
\end{tabular}

Overall SG Ranking based on:

$\{1 . \rightarrow 30$ Percent of: "Trade Factors and U.S. Competitiveness" $\}$

$\{2 . \rightarrow 30$ Percent of: "SG Market growth potential” \}

$\{3 . \rightarrow 20$ Percent: "Key Economic and Energy Sector Investement Indicators" \}

$\{4 . \rightarrow 10$ Percent: "Strength of Domestic Industry" \}

$\{5 . \rightarrow 10$ Percent of: "Energy Storage Growth Potential" $\}$

A-2. The financial report about global new investment in RESSs by technology (source: [8]):

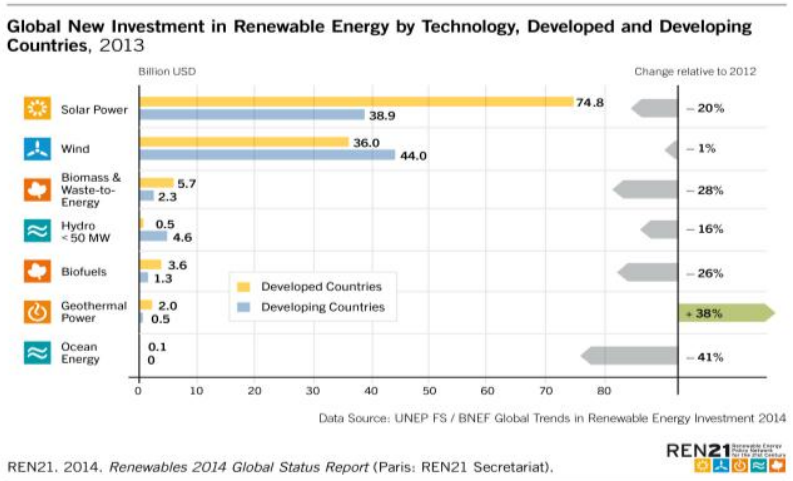


Appendix B: IEEE's comparison between centric approaches based existing grid and SG. (Adapted from [14])

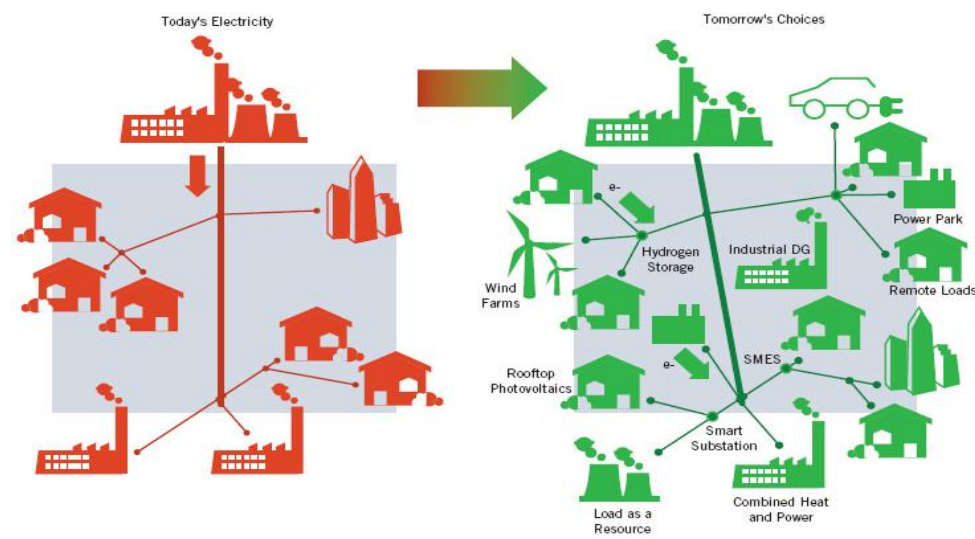

Appendix C: The SG conceptual model reference as defined by the US - NIST framework 1.0 January 2010 (source: [17])

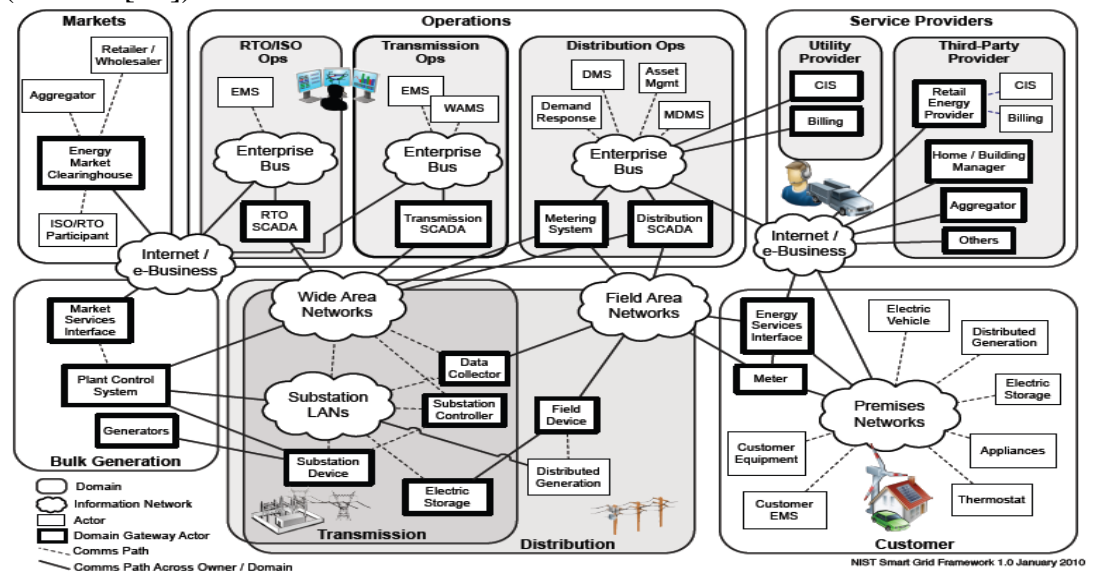

Appendix D: Some required communication technologies for LV Smart Metering, which can be implemented to move towards a SG infrastructure. (Source [18]).

\begin{tabular}{|c|c|c|c|}
\hline Technology & Applications & Data Rate & Specifications/Standards \\
\hline NB-PLC & $\begin{array}{l}\text { Indoor/Outdoor command \& } \\
\text { Control services, AMI }\end{array}$ & $\sim 200 \mathrm{kbps}$ & $\begin{array}{l}\text { PRIME, G3-PLC/IEEE 1901.2, } \\
\text { ITU-T G.hnem (Higher Data Rates) } \\
\text { IEC 61334-5-1, IEC 62056-21, } \\
\text { ISO/IEC 14908-1, Meters \& More } \\
\text { (Lower Data Rates) }\end{array}$ \\
\hline BB-PLC & $\begin{array}{l}\text { In-home applications, Home } \\
\text { Networking }\end{array}$ & $\begin{array}{l}\sim 100 \text { Mbps (IEEE 1901) } \\
\sim 200 \text { Mbps (HomePlug AV) } \\
\sim 1 \text { Gbps (ITU-T) }\end{array}$ & $\begin{array}{l}\text { HomePlug } 1.0 \text { (14Mbps), } \\
\text { HomePlug Turbo (85Mbps), } \\
\text { HomePlug AV (200Mbps) } \\
\text { TIA-1113, IEEE 1901, ITU-T G.hn }\end{array}$ \\
\hline \multirow{2}{*}{ DSL } & \multirow{2}{*}{$\begin{array}{l}\text { Data Transmission over } \\
\text { telephone lines }\end{array}$} & \multirow{2}{*}{256 kbps-100 Mbps } & ITU G.991.1, ITU G.991.2 (SDSL) \\
\hline & & & $\begin{array}{l}\text { ITU G.992.1, ITU G.992.2 (ADSL) } \\
\text { ITU G.993.1, ITU G.993.2 (VDSL) }\end{array}$ \\
\hline ZigBee & AMI & $250 \mathrm{kbps}$ & ZigBee Home Automation \\
\hline $\begin{array}{l}\text { Wireless } \\
\text { Mesh }\end{array}$ & $\begin{array}{l}\text { For communication networks } \\
\text { made up of radio nodes }\end{array}$ & $\begin{array}{l}54,48,36,24,18,12,9,6,4,5 \\
1.5 \text { up to } 300 \text { Mbps for outdoor }\end{array}$ & $\begin{array}{l}\text { IEEE 802.11, } \\
\text { IEEE 802.15, } \\
\text { IEEE 802.16 }\end{array}$ \\
\hline GSM/GPRS & $\begin{array}{l}\text { Mobile functionality }- \text { voice, } \\
\text { data transfer }\end{array}$ & $\begin{array}{l}14.4 \text { kbps (GSM) } \\
56-114 \text { kbps (GPRS) }\end{array}$ & $\begin{array}{l}\text { EN 301349, } \\
\text { EN 301347, } \\
\text { EN 301344 }\end{array}$ \\
\hline $3 G$ & $\begin{array}{l}\text { Mobile functionality }- \text { voice } \\
\text { fast data transfer }\end{array}$ & $\begin{array}{l}\text { over } 0.2 \mathrm{Mbps} \text { up to } 14.7 \mathrm{Mbps} \\
\text { (CDMA, EVDO) }\end{array}$ & UMTS, CDMA 2000, EV-DO, EDGE \\
\hline LTE & $\begin{array}{l}\text { High speed data for mobile } \\
\text { phones and data terminals }\end{array}$ & $\begin{array}{l}100 \text { Mbps (requirement) } \\
\text { up to } \sim 320 \text { Mbps }\end{array}$ & \\
\hline WiMAX & $\begin{array}{l}\text { Mobile Broadband or at-home } \\
\text { broadband connectivity, } \\
\text { Alternative to DSL }\end{array}$ & $\begin{array}{l}\text { up to } 75 \mathrm{Mbps} \text { (IEEE } 802.16 \mathrm{~d} \text { ) } \\
\text { up to } 15 \mathrm{Mbps} \text { (IEEE } 802.16 \mathrm{e} \text { ) }\end{array}$ & $\begin{array}{l}\text { IEEE 802.16, } \\
\text { IEEE 802.16d, } \\
\text { IEEE 802.16e }\end{array}$ \\
\hline LPWAN & $\begin{array}{l}\text { IoT, Smart metering } \\
\text { applications }\end{array}$ & lower than $100 \mathrm{kbps}$ & SigFox, LoRaWAN, NB-IoT \\
\hline
\end{tabular}

